\title{
Spatially Enabling Governments through SDI implementation
}

\author{
Ian MASSER, Abbas RAJABIFARD and Ian WILLIAMSON \\ Centre for Spatial Data Infrastructures and Land Administration \\ Department of Geomatics, University of Melbourne, \\ Victoria 3010, Australia
}

\begin{abstract}
Spatially enabled government requires the development of effective SDIs that will support the vast majority of society, who are not spatially aware, in a transparent manner. This paper addresses three strategic challenges arising out of the need of creating this new environment. The first of these is the challenge for more inclusive models of governance given that SDI formulation and implementation involve a very large number of stakeholders from all levels of government as well as the private sector and academia. The second concerns the promotion of data sharing between different kinds of organisation. In some cases this may require new forms of organisation to carry out these tasks. The third challenge relates to the establishment of enabling platforms to facilitate access to spatial data and the delivery of data related services.
\end{abstract}

\section{Introduction}

Governments can be regarded as spatially enabled 'where location and spatial information are regarded as common goods made available to citizens and businesses to encourage creativity and product development' (Wallace et al 2006, 3). Under such circumstances the vast majority of the public are users, either knowingly or unknowingly, of spatial information. They generally lack an awareness of spatial concepts and principles while many are willing to transparently embrace spatially

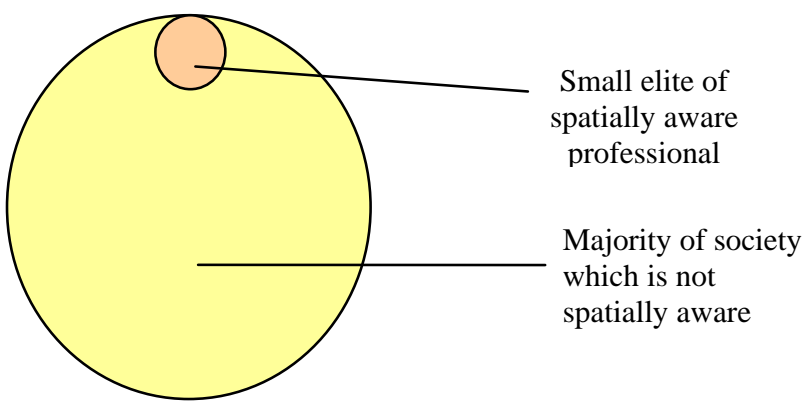

Figure 1: Level of spatial data users and expertise in society enabled infrastructures such as Google Earth (see for example, Barr 2005 and Butler 2006). As a result spatially enabled governments present a number of important challenges for the small elite of spatially aware professionals who have so far dominated the development of the spatial related fields of geography, land administration and environmental science, and particularly those who have an in-depth scientific understanding of spatial concepts . The key challenge is how to develop a spatial data infrastructure (SDI) that will provide an enabling platform in a transparent manner that will serve the majority of society who are not spatially aware as visualised in Figure 1.

One of the most interesting developments in recent years has been the increasing involvement of governments throughout the world in the development of spatial data infrastructures (SDIs), which is an evolving concept and can be viewed as an enabling platform linking data producers, providers and value adders to data users. The US Federal Geographic Data Committee web site defines SDI's as 'the technology, policies, criteria, standards and people necessary to promote geospatial data sharing throughout all levels of 
government, the private and non-profit sectors, and academia. [They] provide a base or structure of practices and relationships among data producers and users that facilitates data sharing and use. [They are] a set of actions and new ways of accessing, sharing and using geographic data that enables far more comprehensive analysis of data to help decisionmakers chose the best course(s) of action'(www.fgdc.gov).

SDIs have become a crucial tool in facilitating how spatial data and spatial information systems are used. They allow the sharing of data, which enables users to save resources, time and effort when trying to acquire new datasets. SDI is said to comprise data, standards, access network, institutions and policies, and human resources (Rajabifard et al. 2004). Such an entity can be enhanced so that it is possible to share in addition to data, business goals, strategies, processes, operations and value-added products which can help to facilitate spatial enablement across government and different jurisdictions.

There are many parallels between the thinking that underlies the development of SDIs and the vision of spatially enabled government outlined above but there are also some important differences. SDI development, as it has emerged over the last fifteen years (Masser 2005), has been often dominated by the concerns of central governments usually without the participation of stakeholders from the sub national levels of government, the private sector and academia. SDIs have also been developed in many cases as a tool for the professional elite rather the population as a whole who are the main beneficiaries of spatially enabled government.

With these considerations in mind this paper explores the challenges that must be overcome to make existing SDIs more appropriate for spatially enabling government. It addresses three strategic challenges arising out of this new environment (Figure 2). The first of these is the need for more inclusive models of governance given that SDI formulation and implementation involves a very large number of stakeholders from all levels of government as well as the private sector and academia. The second concerns the promotion of data sharing between different kinds of organisation. In some cases this may require new forms of organisation to carry out these tasks. The third challenge relates to the establishment of enabling platforms to facilitate access to spatial data and the delivery of data related services.

Spatially Enabled Government

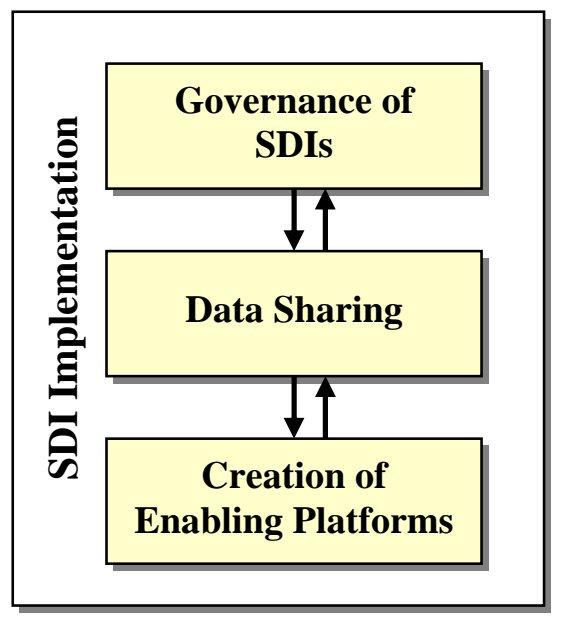

Figure 2: Strategic Challenges

\section{A Vision of Spatially Enabled Government}

Spatially enabled government consists of an overarching vision and a set of tools. The vision is to establish an enabling infrastructure that will facilitate the provision of the place or where or location to all human activities, and government actions, decisions and polices. The enabling infrastructure provides the set of tools combining technical, institutional, legal and policy aspects which can be used to assist the delivery of sustainable development at all levels of government and society. Such spatial enablement allows business transactions to be linked to a place or location and further facilitates the evaluation and analysis of relationships between people, business transactions and government.

A spatial enabled government is one that plans to achieve three broad goals: 
- More effective and more transparent coordination, where voters are able to access the spatial information they require to evaluate the choices made by elected decision makers.

- The creation of economic wealth through the development of products and services based on spatial information collected by all levels of government.

- The maintenance of environmental sustainability through the regular and repeated monitoring of a wide range of spatial indicators distributed throughout the world as a whole.

The first and the last of these goals have been widely discussed in recent years, coordination with particular respect to the potential of electronic government and electronic democracy and sustainability in the context of the United Nations World Summit on Sustainable Development and the realisation on its Millennium Development Goals (Bell 2006). However, it is only relatively recently that the economic potential of the information that is routinely collected by governments all over the world for the information industry has become a part of this vision. The European Commission, for example, came to the conclusion that the European information industry was at a significant disadvantage to its American counterpart. Compared with the United States conditions for re use of public sector information in Europe were opaque and uneven. Nor was it a straightforward matter to identify the documents available for re use in the various national member states. With this in mind the Commission proposed a minimum level of harmonisation across the European Union to facilitate the more effective exploitation of public sector information as an economic resource to promote the development of pan European information products and services (CEC 2003).

Geographic information accounts for a significant proportion of this public sector information. A study carried out by PIRA International (2000, 16) for the European Commission estimated that over half the 68 billion Euro economic value of public sector information in 1999 came directly from geographic information sources and that this figure would have been considerably larger if indirect sources such as the geographic dimensions of economic and social data were taken into account.

Realising this vision of spatially enabled government is dependent on the development of appropriate mechanisms to facilitate the delivery of data and services. These mechanisms should embody the following principles that are the foundation of the INSPIRE initiative that is currently being implemented by the European Commission (CEC 2004):

- Data should be collected once and maintained at the level where this can be done most effectively

- It should be possible to combine seamlessly spatial data from different sources and share it between many users and applications

- Spatial data should be collected at one level of government and shared between all levels

- Spatial data needed for good governance should be available on conditions that are not restricting its extensive use

- It should be easy to discover which spatial data is available, to evaluate its fitness for purpose and to know which conditions apply for its use (http://inspire.jrc.it). 
The most highly developed mechanisms of this kind in operation for such purposes are the SDIs that are currently being developed in more than 50 different countries throughout the world (Masser 2005).

\section{The Governance of SDIs}

It must be recognised that many of the SDI structures that have come into being over the last ten years are not appropriate mechanisms in their current forms for realising this vision of spatially enabled government. In many cases the original driving force behind these initiatives was narrowly focussed around traditional governmental surveying and mapping activities. Consequently, when looking at specific national cases, it will be necessary to consider the extent to which current SDIs are appropriate to operate as the delivery mechanisms for spatially enabled government. A good example of a mismatch of this kind can be found in the US NSDI initiative, which is essentially a federally driven programme (see NAPA 1998)

SDI development over the past fifteen years has seen three main players emerge, federal/national governments, sub-national governments and the private sector, but the role of each has been quite different (Rajabifard et al 2006). Current trends and development within SDIs show that the roles of the three major players are changing to meet the new large-scale focus of many SDIs, especially in the developed world. The previous influence of national governments at both strategic and operational levels has diminished, although there is still a strong case for a strategic national government role in SDI through governance. This can be seen in Europe through the development of the INSPIRE Directive establishing a European environmental SDI that was approved by the Council of Ministers and the European Parliament in November 2006. (CEC 2004).

The operational level of SDI that was originally undertaken by national governments has now moved to the sub-national government level. It is at this level that large-scale land administration data is produced (the most common form of spatial data is land related data). This aids in collecting land taxes, land use planning, the operation of land markets, road and infrastructure development and day-to-day decision making in order to meet sustainable development objectives. The private sector's operational role has also increased and they are leading the drive for greater access to 'people-relevant' data that is utilized to effectively undertake their role within society.

The flow of information between the three main players has also changed. Building of infrastructure generally occurs at a sub-national, bottom-up level with the national government providing the overall framework in which such infrastructure can operate (although national governments do play some role in infrastructure building). This is what is beginning to occur within the development of SDIs, particularly in Australia, Canada and the United States. Communication now flows between these three players, rather than from a top-down national government approach.

Under these circumstances it is necessary to think in terms of more inclusive models of SDI governance. Top priority must be given to the creation of appropriate SDI governance structures which are both understood and accepted by all the stakeholders. This is a daunting task given the number of organisations that are likely to be involved. In the US, for example, there are more than 100,000 organisations engaged in SDI related GIS activities. It will not be possible in most cases to bring all the stakeholders together for decision making purposes 
and structures must be devised that keep all of them informed and give them an opportunity to have their opinions heard.

One solution to this problem is to create hierarchical structures at the national, state and local level for this purpose (Figure 3). The main features of these structures can be seen in the administrative arrangements that have come into being in Australia. The lead Commonwealth government agency for the Australia SDI is the Australia New Zealand Land Information Council (ANZLIC). Each of the members of ANZLIC represents a coordinating body within their jurisdiction (i.e. the Commonwealth Office for Spatial Data Management, the relevant coordination bodies at the state and territory levels and Land Information New Zealand).

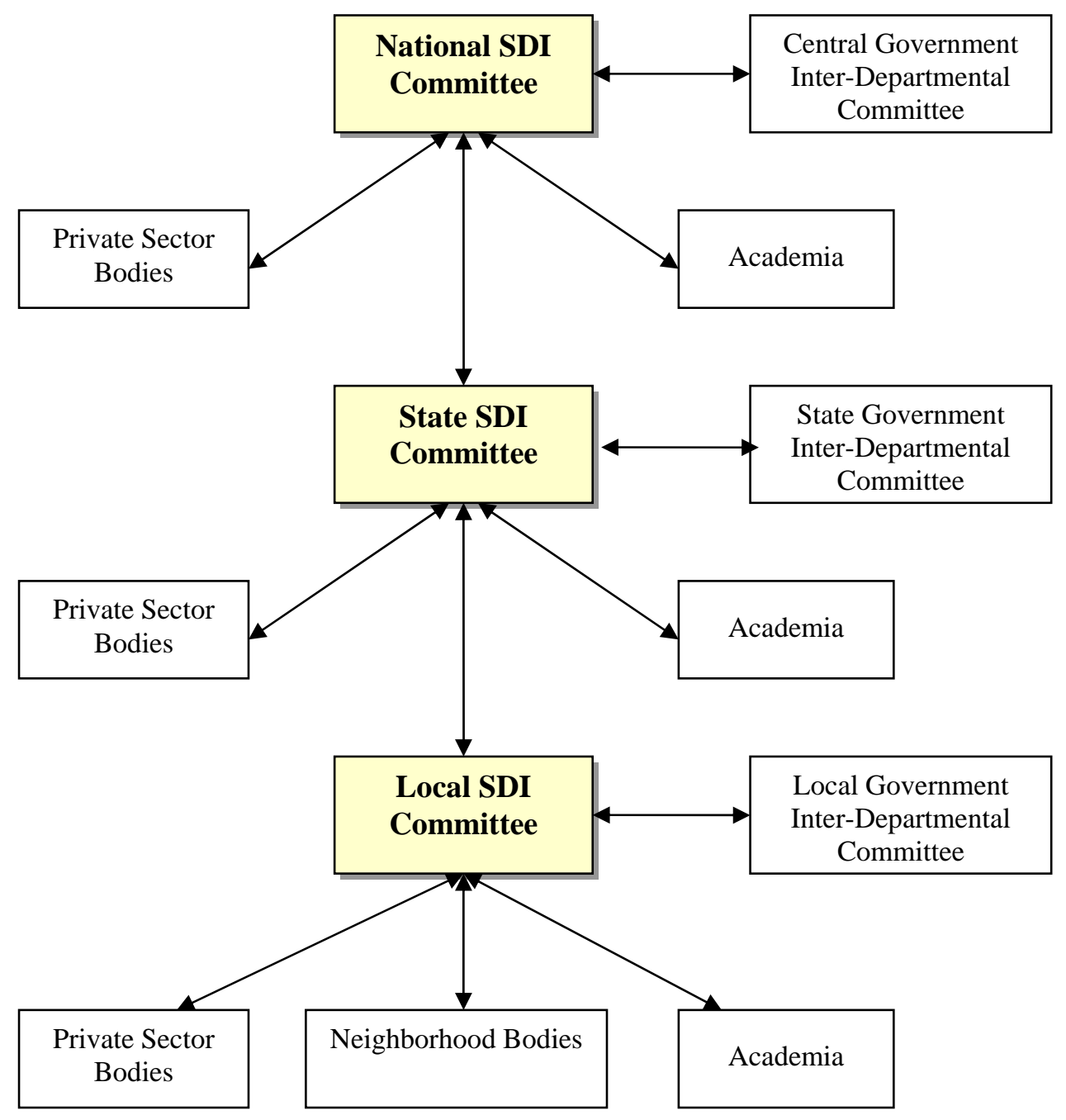

Figure 3: Hierarchical Relationships between National, State and Local Governments Bodies in SDI Implementation

Similar types of body are now coming into being at the state level in Australia to perform similar functions. For example, the state of Victoria set up the Victorian Spatial Council in 2004 to oversee the implementation of the state's Spatial Information Strategy (VSIS). Its role is 'to provide a coordinated whole of industry approach to spatial information policy and development, management and utilisation in Victoria, by undertaking a spatial information 
management role, and acting as a mechanism for cross-sectoral consultation and liaison.' (Department of Sustainability and Environment 2004,3). Its membership is set at a maximum of 13 members drawn from state government (3), local government (2), federal government (1), academia (2), the professions (2) and the private sector (2). Each of the Council's members is responsible for

- Ensuring that initiatives to be considered by the Council are discussed adequately within their own sector prior to Committee meetings to the extent required to enable the Council member to be able to speak on behalf of his/her sector.

- Briefing the members of their respective sectors on matters considered by the Council and its response.

- Proactively supporting implementation of the VSIS within their sector (p.10).

In this way the Council provides a mechanism for involving all the stakeholders in the State's SDI.

Hierarchical governance structures are also beginning to emerge in other parts of the world, particularly in countries where some administrative responsibilities relating to geographic information are devolved to the state or provincial level. They are built, for example, into the German national SDI (Lenk 2005) and the Malaysian MyGDI initiative (Ahmed 2004), and to some extent in the US 50 states initiative that is backed by the FGDC and the National States Geographic Information Council (Robinson and Burgess 2006). Elements of these structures can also be seen at the regional level in the development of GIS Flanders in Belgium (www.gisvlaanderen.be), the Catalonian SDI in Spain (Guimet 2004), and Northern Ireland's MOSAIC in the United Kingdom (Mason 2006).

It is important that these governance structures should be as inclusive as possible from the outset of a SDI initiative so that all those involved can develop a shared vision and feel a sense of common ownership. Otherwise it may be difficult or even impossible to bring new participants into a SDI initiative at a later stage. This is likely to be a challenging task that may slow down the progress of the work in the short term but building up a base for future collaboration is an essential prerequisite for the long term success of the SDI.

The findings of this analysis highlight the challenges that need to be faced in developing inclusive governance structures to facilitate more effective SDI implementation for spatially enabled government. This represents a major departure from existing practices in many of the countries that have embarked on SDI development over the last fifteen years.

\section{Data Sharing}

Data sharing between organisations featured prominently in the initial discussions about SDIs. The US Mapping Science Committee's landmark report, 'Towards a coordinated spatial data infrastructure for the nation,' devoted a whole chapter to the sharing of spatial data. The rationale for a spatial data sharing programme is 'to increase benefits to society arising from the availability of spatial data. The benefits will accrue through the reduction of duplication of effort in collecting and maintaining of spatial data as well as through the increased use of this potentially valuable information.' (MSC, 2003, 89) It also argued that this programme 'must do more than just disseminate spatial data collected by federal agencies. The richness and utility of the program is substantially enhanced by having participation of donors from state and local governments, academic, and the private sector.'(p.104). With this in mind the Committee recommended that the 'FGDC should 
establish a data sharing committee with the objective of providing the policy making and leadership to launch, maintain, and operate the proposed program' (p.104).

These proposals do not take account of the complexity of data sharing in practice. The intricate nature of the relationships involved in organisational and inter organisational data sharing and the legal, economic, cultural and personal privacy related issues associated with these activities have been highlighted in the report of an expert meeting convened by the National Centre for Geographic Information and Analysis. The editors of this report, Harlan Onsrud and Gerard Rushton (1995), define the issues involved in the following terms: 'Sharing of geographic information involves more than a simple data exchange. To facilitate sharing, the GIS research and user communities must deal with both the technical and institutional aspects of collecting, structuring, analysing, presenting, disseminating, integrating and maintaining spatial data.'

Subsequently Uta Wehn de Montalvo (2003) has explored spatial data sharing perceptions and practices in South Africa in some depth from a social psychological perspective. This study utilises the theory of planned behaviour as a framework for analysis. This theory suggests that personal and organisational willingness to share data depends on attitudes to data sharing, social pressures to engage or not engage and perceived control over data sharing activities of key individuals within organisations. The attitude component consists of four domains: resources, organisational activities, the strategic position of an organisation and social outcomes. The social pressures component consists of five domains: GIS community pressure, market pressure, institutional pressure, organisational pressure and moral norms. The perceived control over data sharing component takes account of internal factors such as technical skills, interpersonal skills and resource control as well as external factors such as dependence on others, sharing opportunities.

The findings of her research show how the beliefs underlying these three components can be operationalised in a questionnaire and ranked by respondents to gain a better understanding of the willingness of organisations to share information. The outcomes of her quantitative analysis generally bear out the relationships postulated in this theory and give valuable insights into the factors that determine the willingness to share spatial data. They also show that there is only a relatively limited commitment amongst those involved to promote data sharing in high profile initiatives such as South Africa's National Spatial Information Framework. The findings of this research are supported by a number of studies of local government data sharing in the US carried out by Harvey and Tulloch (2006) which suggest that local government data sharing is largely informal in nature and is undertaken mainly to support existing government activities. In this environment NSDI principles are largely irrelevant for the majority of the surveyed governments.

Notwithstanding these conceptual and operational problems the SDI literature contains many positive reports on inter organisational data sharing in practice. A study of more than 200 central and local government organisations commissioned by the e-government unit of the UK Cabinet Office (2005) found that 49 per cent of respondents claimed that they were participating in data sharing projects but provided only limited detail about the nature of such projects. One case that is cited in the report is the Forth Valley GIS which is a joint public sector partnership unit providing corporate GIS services to three neighbouring local authorities in Scotland, Clackmannanshire, and Falkirk and Stirling Councils. Ad hoc arrangements of this kind are not uncommon elsewhere in the United Kingdom and are particularly well developed in the United States. For example, the well established New York State GIS data sharing cooperative has 584 members. More than 200 of these are from local government, 111 from not for profit organisations, 109 are from academia, while state and county level government organisations accounting for the bulk of the remainder 
(www.nysgis.state.ny.us/coordinationprogram/cooperative/index.cfm).

Data sharing in the course of SDI implementation will often require a minimum of a written agreement between the parties concerned and nay also involve the creation of new kinds of organisational structures. These can take various forms. Masser's (2005 chap 5) analysis of the different kinds of organisational structures that have already emerged in the US, Australia and Canada to facilitate data sharing during SDI implementation shows that at least five different types of partnerships are already in operation. These range from the restructuring of existing government agencies to the establishment of joint ventures involving different combinations of the key stakeholders (Table 1).

Table 1: Examples of organisational structures created to facilitate data sharing during SDI implementation

\begin{tabular}{|c|c|c|}
\hline Type & Status & Driving force \\
\hline Restructuring & $\begin{array}{l}\text { Within government structures } \\
\text { External to government } \\
\text { structures }\end{array}$ & $\begin{array}{l}\text { Creation and maintenance of an } \\
\text { integrated land information database } \\
\text { Delivery of wide range of eGovernment } \\
\text { services }\end{array}$ \\
\hline Joint ventures & $\begin{array}{l}\text { Consortium of data producers } \\
\text { Joint venture by key data users } \\
\text { Joint venture by wide range of } \\
\text { data producers and users }\end{array}$ & $\begin{array}{l}\text { Integration of datasets held by state and } \\
\text { commonwealth agencies } \\
\text { Maintenance and dissemination of core } \\
\text { datasets } \\
\text { Creation and sharing of core datasets }\end{array}$ \\
\hline
\end{tabular}

The simplest case is the merger of various government departments with responsibilities for collecting geographic information. The driving force for this restructuring is the perceived administrative benefits associated with the creation of an integrated database for the agency as a whole. Western Australia's Shared Land Information Platform (SLIP) provides increased cross governmental access to the wide range of land and related spatial information within both the Department of Land Information and other governmental agencies (www.walis.wa.gov.au). . The development and implementation of SLIP has both a horizontal and vertical focus, with the horizontal being whole-of-government services and access to data and the vertical being a focussed business model providing tailored services to an aspect of government management. One of the major challenges in creating a SLIP is the need for effective coordination across all government agencies involved.

An alternative strategy is to set up a special government agency outside the existing governmental structure with a specific remit to maintain and disseminate core datasets. Service New Brunswick in Canada is a good example of such a strategy (www.snb.ca). It is a Crown Corporation owned by the Province of New Brunswick. It was originally set up to deal with matters relating to land transactions and topographic mapping for the Province as a whole. Since 1998 it has shifted its position to become the gateway for the delivery of a wide range of basic government services as well as national SDI implementation (see next section). 
There are also some interesting examples of joint ventures between different groups of the stakeholders in SDI implementation. The simplest case is a data producer driven joint venture such as the Australian Public Sector Mapping Agencies consortium (PSMA) that was set up in 1993 to create an integrated national digital base map for the 1996 Census of Population (www.psma.com.au). The driving force behind this partnership was the recognition the whole is worth more than the sum of the parts in that there are clear benefits for the nation to be derived through the assembly of national data sets from data held by the consortium members.

The other two types of joint ventures involve more complex structures. The Large Scale Base Map of the Netherlands (www.gbkn.nl) is a good example of a joint venture to create and maintain key elements of a spatial data infrastructure. This involves a continuing commitment to share the costs involved between a number of public sector agencies from central and local government as well as the private sector utility companies. The national joint venture agency that manages the project is consequently a case of a public private partnership of data users that has been operating at the local, provincial and national levels for more than ten years.

Finally, initiatives such as the MetroGIS collaborative in the Minneapolis St Paul metropolitan region of the US bring together a large number of data producers and data users (www.metrogis.org). Such initiatives are both more ambitious and more open ended in their potential for development than either of the other joint ventures. MetroGIS is a collaborative venture between the spatial data producer and user communities to assemble, document, and distribute geospatial data commonly used by the more than 300 local and regional government units serving the seven-county Minneapolis - St. Paul metropolitan area (Masser and Johnson 2006). It is a voluntary organization that provides an effective forum to identify common geospatial data related needs, collectively define the organisational and technical solutions needed to address those needs, and share geospatial data knowledge. MetroGIS has no legal standing and, as such, cannot own data, hire staff, or finance projects. It relies on its stakeholder organizations to develop and maintain all data, develop and support datadistribution tools, and finance its staff and project needs.

The findings of this analysis indicate some of the challenges that need to be resolved in order to promote inter organisational data sharing on an unprecedented scale for spatially enabled government. In many cases this will require either major changes in existing organisational structures or the creation of new structures to facilitate data sharing activities.

\section{The Creation of Enabling Platforms}

Development of SDIs have played a major role in helping to form the concept of a spatially enabled platform. Initially SDIs were implemented as a mechanism to facilitate access and sharing of spatial data hosted in distributed GISs. Users however now require precise spatial information in real time about real world objects and the ability to develop and implement cross-jurisdictional and inter-agency solutions to priorities such as emergency management, natural resource management, water rights and animal, pest and disease control.

In order to achieve this, the concept of an SDI is moving to a new business paradigm, where SDI is emerging as an

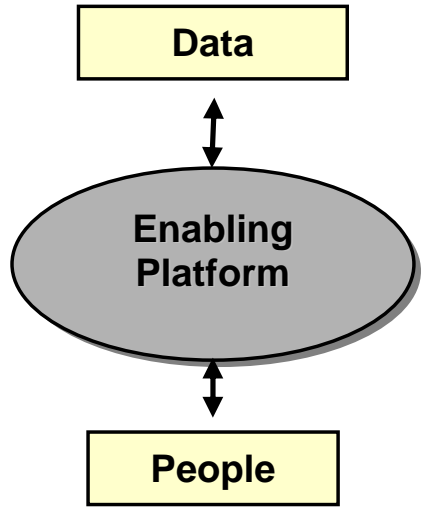

Figure 4: Connecting People to Data 
enabling platform to promote the partnership of spatial information organisations (public/private) to provide access to a wider scope of data and services, of size and complexity that is beyond their individual capacity.

SDI as an enabling platform can be viewed as an infrastructure linking people to data (Figure 4) through linking data users and providers on the basis of the common goal of data sharing. The benefits of SDI in enabling this sharing of information have been documented, however an SDI does not necessarily break down the barriers between jurisdictions. Just because different information can be gained about a state for example from different jurisdictional levels, does not mean that the information will necessarily be compatible (it may not be of the same accuracy or have the same specifications, utilize the same symbology, etc). There is now a need to move beyond a simple understanding of SDI and create a common rail gauge to aid in implementing initiatives that solve cross-jurisdictional and national issues.

The technical basis for delivery of enabling platform should be through an interoperability architecture based on distributed, custodial data management and open standards. This would provide uniform and consistently managed access to distributed web services operated by authoritative custodians. This architecture would allow initiatives to grow in an open environment that gives government and agencies the ability to operate in an integrated manner (Rajabifard et al. 2005). This creates an opportunity for a whole of government initiative to develop from the often-fragmented developments at different levels.

The ability to deliver the concept of spatially enabled platform however will also require an investigation of the way that data will be stored in the future. The ability to allow massive consolidation of spatial data sets across all jurisdictions may enable the creation of a seamless platform (which covers both land and marine environments), although there is the need to look closely at the advantages and disadvantages of both a distributed data model verses a consolidated model. It will be important that the concept is based upon and takes advantage of the latest technologies, standards and metadata application in order to deliver an interoperable environment. One of the key objectives of SDI is to facilitate the interoperable environment through the ability to integrate multi-source datasets.

With this in mind, it is acknowledged that new data base management software and technology promises to change the way that data is stored and the underlying technology that will support and drive the enabling platform in general. The benefits of such technology are already being seen in the development of the Geocoded National Address File (GNAF), the concept of virtual libraries, the emerging GRID computing technologies and super servers throughout the world. However there is general acknowledgement that the major challenges in implementing an enabling platform are not technical, but institutional, legal and administrative in nature.

The enabling platform will be the main gateway to discover, access and communicate spatially enabled data and information about the jurisdiction. Such an entity can be enhanced so that it is possible to share in addition to data, business goals, strategies, processes, operations and value-added products. In this environment all types of organisations participating (including governments, industries, and academic) can gain access to a wider share of the information market ensuring more transparent and effective information coordination. This is done through organisations providing access to their own spatial data and services, and in return, becoming a contributor and hence gaining access to the next generation of different and complex services. The vision is to facilitate the integration of existing government spatial data initiatives for access and delivery of data/information. This integration would be based on common standards and business understanding and combines 
distributed functions provided by participating organisations to deliver services which structured and managed in such a way that to be seen by third parties as a single enterprise.

The benefits of such an environment will be more than just the representation of feature based structures of the world; it will also include the administration and institutional aspects of such features, enabling both technical and institutional aspects to be incorporated into decision-making (Rajabifard et al. 2005a).

Following this direction, in Australia for example, they have started to develop an enabling platform called Virtual Australia. The concept and delivery of Virtual Australia aims to enable government and other users from all industries and information sectors to access both spatial information (generally held by governments) and applications which utilise spatial information (developed by the private sector and governments). According to Rajabifard et al. (2006), Virtual Australia is a vehicle from which both textual and spatial data are utilized to form a range of supported functions for those within the industry as well as non-spatial and non-technical user groups. Each state jurisdiction has a range of initiatives and functions being both used and created often in isolation from one another. The creation of Virtual Australia will help to modularize the development of SDI - creating services and functions that can be utilized at further levels up the information chain, including across jurisdictions.

With this in mind, Virtual Australia is an enabling platform that supports the vision of spatially enabled government by providing a major point of discovery and communication to complete, correct and current information about the natural and built environment and related affordable spatial information applications, in a useable and readily available manner at anytime and in anyplace.

Another example is the Geospatial One-Stop (GOS) in the USA, which is one of three major initiatives (Federal Geographic Data Committee (FGDC), Geospatial One-Stop (GOS) and The National Map initiative) driving the development of a National SDI (NSDI) for USA. The GOS is one of 24 e-Government priorities that are aiming to make it easier, faster and less expensive for all levels of government and citizens to access spatial information (Ryan et al. 2004). From a policy perspective, it adds three unique benefits to the implementation of the NSDI including:

- Raising the visibility of the strategic value of geographic information

- Increasing federal accountability for geospatial data stewardship, and

- Establishing a collaborative model for an intergovernmental initiative.

The establishment of the GOS also gives the implementation of an NSDI a sense of urgency and importance. The GOS implements the basic elements of the NSDI by providing an Internet portal to facilitate data sharing and encourage decision support across all jurisdictional levels of the country. GOS will rely on the National Map as the underlying provider of base content for all other GOS supplied datasets. This gives the USA a base layer of fundamental data from which all other jurisdictional levels are able to work from. This type of initiative is also important in the creation of a seamless SDI between all jurisdictional levels as well as creating spatially enabled government vision.

The development of Service New Brunswick (SNB) is also another example which is very relevant to the concept of a 'enabling platform'. SNB is the Canadian Province of New Brunswick's gateway for the electronic delivery of a wide range of basic government services. Its mission is "to improve the accessibility of government services and to be stewards for authoritative public information" and provides "simple, fast and secure access to products, services and information” (SNB 2005). It is interesting to note that the Vision 
for SNB is "government services on time, every time, everywhere" (SNB 2004), a vision not dissimilar to that for the Australian Cooperative Research Centre for Spatial Information (CRC-SI). SNB has four main lines of business including Property Assessment (all land, buildings and improvements), Registries (real and personal property registries), Government Service Delivery (more than 197 government services) and Geographic Information Infrastructure (creation and maintenance of the control survey network and base mapping data). Through a web portal, individuals and business have access to a range of services including property assessment, tickets for festivals and attractions, driving and vehicle registration, Fredericton District Soccer Association registration and a range of land and property services.

Based on these examples, the creation of an enabling platform would lower barriers to access and use of spatial data, to both government and the wider community within any jurisdiction, and particularly to the spatial information industry. If barriers are minimised, then entities would be able to pursue their core business objectives with greater efficiency and effectiveness. In particular, industry would be able to reduce their costs, which would encourage investment in capacity for generating and delivering a wider range of spatial information products and services to a wider market.

Having said that, in order to develop a successful and functioning platform requires a set of concepts and principles to enable the design of an integration platform that facilitates interoperability and inter-working of functional entities within a heterogeneous environment. The spatial data communities within any jurisdiction can benefit from the various models and tools that have been developed in other jurisdictions for integrated modeling, as well as the work of the Open GIS Consortium (OGC) to develop standard, interoperable access interfaces, to facilitate access to GIS services over the Internet (Web Services, Internet GIS).

\section{Conclusions}

This paper has considered a number of strategic issues relating to the implementation of SDIs to spatially enable governments. It reviewed and assessed current development of spatial information initiatives and activities within different jurisdictions internationally outlining an overview of current practice and challenges with the aim to help move the vision of enabling platform towards the creation of a strategy and roadmap for the realization of SDI as a framework to spatially enable governments through building institutional capacity amongst all sectors of the spatial information community.

Three strategic challenges that must be taken into account when implementing SDIs to spatially enable government have been addressed in this paper. The first of these indicates the need for new and more inclusive models of governance to enable the very large number of stakeholders from all levels of government as well as the private sector and academia to participate in the management of the processes of SDI implementation. The findings of the analysis also suggest that the emphasis has shifted away from the central government organisations that played a leading role in the initial development of SDIs towards the local government and private sectors in terms of SDI implementation.

The second challenge considered the strategic questions associated with data sharing between different kinds of organisation. The findings of the analysis suggest that data sharing on a massive scale will be needed for SDIs to become fully operational in terms of spatially enabled government. This level of data sharing is likely to require considerable changes in the organisational cultures of the participants and may require new organisational structures to effectively manage this process in some cases. 
The third challenge relates to the establishment of enabling platforms to facilitate access to spatial data and the delivery of data related services. It can be viewed as an infrastructure linking people to data through linking data users and providers on the basis of the common goal of data sharing. Further, this infrastructure would be a vehicle from which both textual and spatial data are utilized to form a range of supported functions for those within the industry as well as non-spatial and non-technical user groups.

In summary, the paper has discussed three strategic challenges that must be taken into consideration during the implementation of SDIs to support spatially enabled governments. It shows some examples of the ways in which these challenges are being addressed in both research and practice. However, the scale of the efforts that will be required to overcome these challenges should not be under estimated. Spatially enabled governments will bring with them considerable benefits to both decision makers and society at large but also require a high level of networking skills and capacity building activities from those professionally involved to deliver these benefits.

\section{Acknowledgements}

The authors would like to acknowledge the support of the members of the Centre for SDIs and Land Administration at the Department of Geomatics, the University of Melbourne, in the preparation of this paper and the associated research. They would also like to acknowledge the support of the Department of Sustainability and Environment, Government of Victoria, Australia in this research. However, the views expressed in the paper are those of the authors and do not necessarily reflect the views of these groups.

\section{References}

Ahmad, M. H (2004). MyGDI: intelligent access to geospatial information, GIS@Development, September.

Barr, R., (2005). Disruptive technologies, Geoconnexion, October, also available at http://www.geoconnexion.com/magazine/article.asp?ID=2409 (last accessed 25 October 2005).

Bell, K. (2006). World Bank Support for Land Administration and Management: Responding to the Challenges of the Millennium Development Goals, FIG Congress 2006, Munich, Germany, October 8-13, 2006.

Butler, D. (2006) Virtual globes - the web wide world, Nature, 439, 776-778

Cabinet Office (2005) Geographic information: an analysis of interoperability and information sharing in the United Kingdom, London: e Government Unit, Cabinet Office

Commission of the European Communities, (CEC), (2003). The reuse of public sector information, Directive 2003/98/EC of the European Parliament and of the Council, Official Journal of the European Union, L345, 90-96.

Commission of the European Communities, (CEC), (2004). Proposal for a Directive of the European Parliament and the Council establishing an infrastructure for spatial information in the Community (INSPIRE), COM (2004) 516 final, Brussels: Commission of the European Communities.

Department of Sustainability and Environment (DSE), (2004). Terms of reference for the Victorian Spatial Council, www.land.vic.gov.au (last accessed 5 March 2006) 
Guimet, J., 2004. Four rules to set up a basic (local) SDI: the process of creation of the spatial data infrastructure of Catalonia (CSDI/IDEC) - experiences and conclusions, Proceedings of GSDI 7 , Bangalore, India.

Harvey, F. and D. Tulloch, (2006). Local government data sharing: evaluating the foundations of spatial data infrastructure, International Journal of GIS, 20, 743-768.

Lenk, M., 2005. Coordination of national SDI in Germany, Proceedings of the 11th EC-GI and GIS workshop, Alghero, Italy

Mason, N., 2006. Crossing boundaries - GIS for all in Northern Ireland, GEOinformatics, 9, (2), 5051.

Masser, I. (2005), GIS worlds: creating spatial data infrastructures, Redlands CA ESRI Press.

Masser, I., and R. Johnson, (2006) Implementing SDIs through effective networking: the MetroGIS Geospatial Data Collaborative, GeoInformatics, 9, (6), 50-53.

National Academy of Public Administration (NAPA) (1998). Geographic information in the 21st century: building a strategy for the nation, Washington: National Academy of Public Administration.

National Research Council, (1993), Toward a coordinated spatial data infrastructure for the nation, Mapping Science Committee, Washington D.C: National Academy Press.

Onsrud, H. and G. Rushton (eds.) (1995) Sharing geographic information, New Brunswick NJ: Centre for Urban Policy Research.

Pira International Ltd, University of East Anglia, and Knowledge Ltd. (2000), Commercial Exploitation of Europe's Public Sector Information. Luxembourg: EC DG INFSO.

Radwan, M., Alvarez, A., Onchaga, R. And Morales, J. (2003), Designing an Integrated Enterprise Model to support Partnerships in the Geo-Information Industry, MapAsia, 2003.

Rajabifard, A., Mansourian, A., Valadan Zoej, M.J. and Williamson, I.P., (2004), Developing Spatial Data Infrastructure to Facilitate Disaster Management, Proceedings of GEOMATICS'83 Conference, 9-12 May, Tehran, Iran.

Rajabifard, A., Binns, A. Masser I. and Williamson, I. (2006), The role of sub national government and the private sector in future spatial data infrastructures, Vol 20, No 7, International Journal of GIS, 727-741.

Rajabifard, A., Binns, A. and Williamson, I. (2006), Virtual Australia - Concepts and Principles, Spatial Science Journal, Special Edition on Spatial information and spatial data infrastructures June 2006. Vol. 51, No. 1.

Rajabifard, A. Binns, A., and Williamson, I.P. (2005), Creating an Enabling Platform for the Delivery of Spatial Information', Proceedings of the Spatial Science 2005 Conference, 14-16 September, Melbourne, Australia.

Robinson, M. and B. Burgess (2006). The fifty states initiative: building a strong NSDI, GeoWorld, September.

Ryan, B., DeMulder, M., DeLoatch, I., Carie, H. and Siderelis, K. (2004), A Clear Vision of the NSDI, Federal Geographic Data Committee Newsletter, 2004 Winter Edition.

SNB (2004), Annual Report 2003-2004, Service New Brunswick, http://www.snb.ca, accessed 14 February 2006.

SNB (2005), Service New Brunswick Home Page, http://www.snb.ca, accessed 14 February 2006.

Wallace, J. I. Williamson A. Rajabifard and R. Bennet (2006) Spatial information opportunities for government, Spatial Science Journal Special Edition on Spatial information and spatial data infrastructures, June 2006, Vol. 51, No. 1.

Wehn de Montalvo, U., 2003. Mapping the determinants of spatial data sharing, Aldershot: Ashgate. 
Williamson, I.P., Rajabifard, A. and Feeney, M. (Eds), (2003) Developing Spatial Data Infrastructures: From Concept to Reality, Taylor \& Francis, UK. 


\section{University Library}

- MIN E R VA A gateway to Melbourne's research publications

Minerva Access is the Institutional Repository of The University of Melbourne

Author/s:

MASSER, IAN; RAJABIFARD, ABBAS; Williamson, Ian P.

Title:

Spatially enabling governments through SDI implementation

Date:

2008

Citation:

Masser, I., Rajabifard, A., \& Williamson, I. P. (2008). Spatially enabling governments through SDI implementation. International Journal of Geographical Information Science, 22(1), 5-20.

Publication Status:

Published

Persistent Link:

http://hdl.handle.net/11343/33586

File Description:

Spatially enabling governments through SDI implementation 


\section{University Library}

\section{- M M I N E R VA A gateway to Melbourne's research publications}

Minerva Access is the Institutional Repository of The University of Melbourne

Author/s:

Masser, I;Rajabifard, A;Williamson, I

Title:

Spatially enabling governments through SDI implementation

Date:

2008-01-01

Citation:

Masser, I., Rajabifard, A. \& Williamson, I. (2008). Spatially enabling governments through SDI implementation. INTERNATIONAL JOURNAL OF GEOGRAPHICAL INFORMATION SCIENCE, 22 (1), pp.5-20. https://doi.org/10.1080/13658810601177751.

Persistent Link:

http://hdl.handle.net/11343/31762 